\title{
Study on Application of Ventilation Heat Transfer in Building Energy Conversation
}

\author{
Xiang MAO ${ }^{1, a}$, Jun-Ling YANG ${ }^{1, c}$, Zhen-Tao ZHANG ${ }^{1, b,{ }^{*}}$ and Lu-Wei YANG ${ }^{1, d}$ \\ ${ }^{1}$ Technical institute of physics and chemistry of CAS, Beijing, 100190, China \\ a694910738@qq.com, byangjunling_hust@126.com, 'czth1@163.com, \\ dIwyang2002@mail.ipc.ac.cn \\ ${ }^{*}$ Corresponding author
}

Keywords: Natural ventilation, Heat exchanger, Energy saving.

\begin{abstract}
Ventilation is a basic requirement for building comfort and the power consumption is higher for mechanical ventilation, in this paper, the heat exchanger with natural ventilation is designed and experiment studied. The results show that the temperature exchange effectiveness, moisture exchange efficiency and enthalpy exchange efficiency are all related to the temperature difference, humidity difference and flow rate. When the Air rate flow is higher than $53 \mathrm{~m} 3 / \mathrm{h}$ and the temperature difference is more than $10^{\circ} \mathrm{C}$. Natural ventilation can meet the ventilation requirements of an ordinary bedroom. Enthalpy exchanger with natural ventilation is more energy saving than mechanical ventilation
\end{abstract}

\section{Introduction}

In the modern society, people spend $90 \%$ time in indoors. Therefore, people pay more and more attention to indoor air quality (IAQ) and comfortable indoor environment [1]. Ventilation is one of the most effective ways to improve the IAQ. However, increased the air ventilation will result in a significant increasing in the building energy consumption. Air heat recovery technology can ease the contradictory of IAQ and the increasing energy consumption. Therefore, it is necessary to use enthalpy exchangers to recover the heat and moisture of exhaust air.

The plate-type enthalpy exchanger is usually constructed in a cross-flow arrangement, for convenience in air ducts sealing and separation of two air streams. A schematic of the cross-flow enthalpy exchanger is shown in Fig.1. Outdoor air and exhaust air flow through the passages in a cross-flow arrangement. The enthalpy exchanger is composed of paper or sheet materials collecting sensible and latent heat simultaneously [2-4].These materials are fabricated into a continuous plate type in corrugated form. Sensible heat is collected at the surface of the honeycomb through the temperature difference of indoor and outdoor air, and the latent heat is returned by the coating on the honeycomb, which is impregnated with a hygroscopic and dehumidifying agent [5].

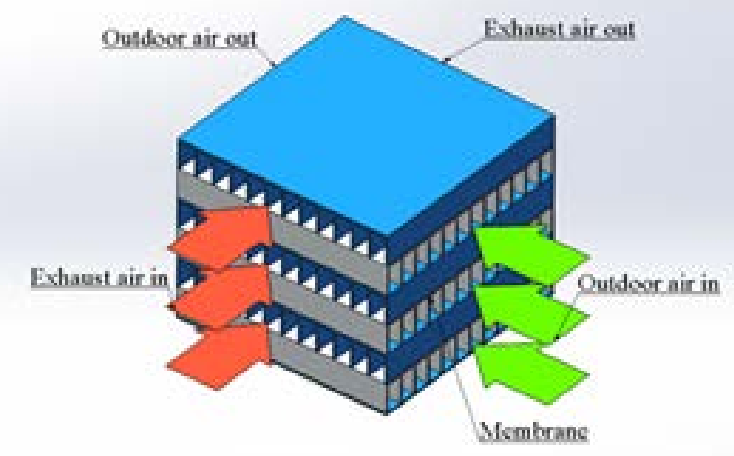

Fig. 1 Schematic of a cross-flow enthalpy exchanger with membrane cores 
Natural ventilation is an important and efficient passive technique to reduce building energy consumption and improve IAQ. However, due to the weak driven force of natural ventilation, i.e., wind pressure or thermal pressure, the natural ventilation rate is usually smaller than that of mechanical ventilation. In present work, the enthalpy exchanger is designed with natural ventilation, see Fig.3.

\section{Experimental Setup}

The temperature transfer effectiveness (or the sensible transfer effectiveness) is given by:

$$
\varepsilon_{T}=\frac{\rho_{O} c_{p O} v_{O}\left(T_{O i}-T_{O o}\right)}{\left(\rho c_{p} v\right)_{\min }\left(T_{O i}-T_{E i}\right)} .
$$

The absolute humidity ratio exchange effectiveness (or the latent heat transfer effectiveness) is given by:

$$
\varepsilon_{h}=\frac{\rho_{O} v_{O}\left(\omega_{O i}-\omega_{O o}\right)}{(\rho v)_{\min }\left(\omega_{O i}-\omega_{E i}\right)} .
$$

The enthalpy exchange effectiveness (or the total transfer effectiveness) is given by:

$$
\varepsilon_{e}=\frac{\rho_{O} v_{O}\left(h_{O i}-h_{O o}\right)}{(\rho v)_{\min }\left(h_{O i}-h_{E i}\right)} .
$$

A schematic of the test is shown in Fig.2.Four measuring points are in the duct straight section, air flow is measured by traverse method, and the S-type Pitot tube and torus method are used to measure dynamic pressure.

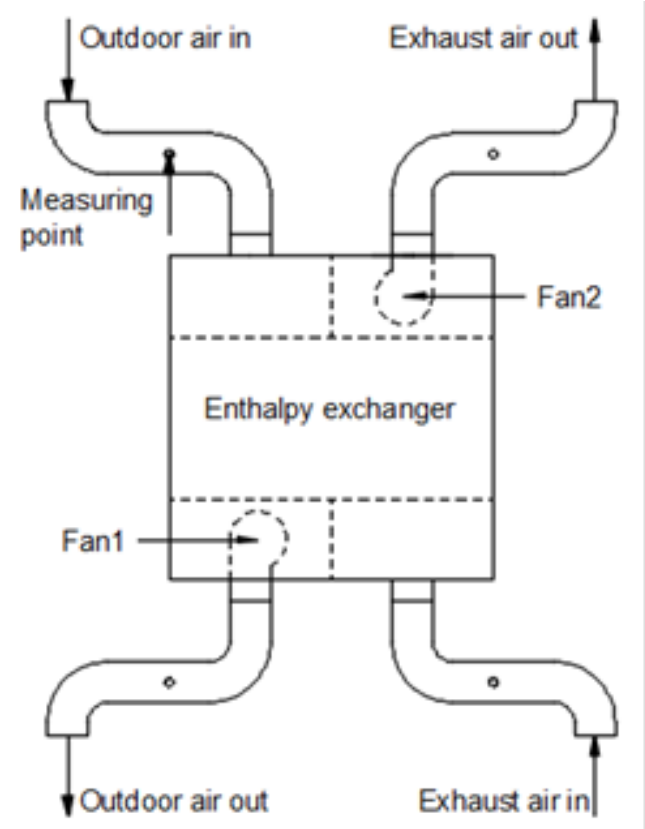

Fig. 2 The schematic of the experimental setup

Indoor air gets into enthalpy exchanger from upper opening, heat transfer occurs with the outdoor air and the temperature decreases, see Fig 3. Temperature changing leads to differences in density which results in a pressure difference. The pressure difference promotes air flow. The pressure difference is given by:

$$
\Delta p_{\text {Heat }}=\rho g h\left(\rho_{\text {out }}-\rho_{\text {in }}\right) .
$$



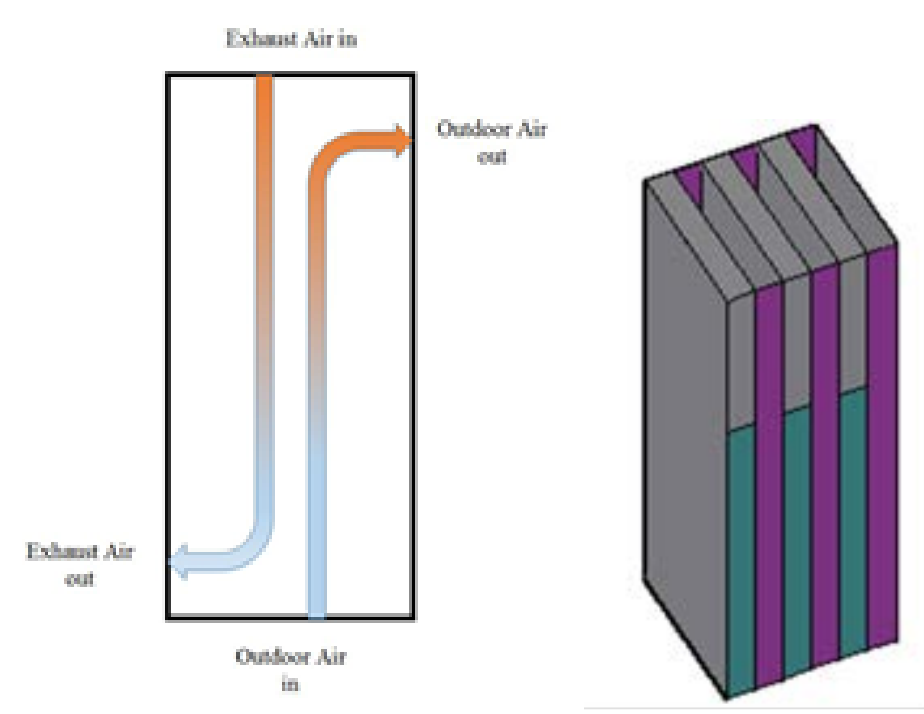

Fig. 3 Enthalpy exchanger with natural ventilation

Thermal expansion coefficient is given by:

$$
\begin{gathered}
\beta=-\frac{\frac{d \rho}{\rho}}{d T} . \\
\mathrm{d} \rho=-\beta p \mathrm{dT} .
\end{gathered}
$$

The pressure difference of the enthalpy exchanger is given by:

$$
\Delta p_{\text {Heat }}=\beta \rho_{\text {out }} g h \varepsilon_{T}\left(T_{\text {oi }}-T_{E i}\right) \text {. }
$$

The channel length is much greater than channel height, $\operatorname{Re}<1000$. Air flow fully develops laminar in enthalpy exchanger. The pressure drop is given by:

$$
\Delta \mathrm{p}=\frac{\lambda \rho L v^{2}}{2 D e} .
$$

The condition of process is given by:

$$
\Delta p_{\text {heat }}-\Delta p \geq 0 \text {. }
$$

Power consumption of heating for natural ventilation is more than mechanical ventilation, the value is:

Energy efficiency is given by:

$$
W_{T}=\frac{Q \rho \Delta T}{C O P}
$$

$$
\eta=\frac{W_{F}-W_{T}}{W_{F}} \times 100
$$

In which WF is the power consumption of the fans used in the mechanical ventilation.

\section{Results and Discussions}

Fig. 4 shows variation of the effectiveness of enthalpy exchanger with air flow rate. In this experiment, the temperature and humidity of indoor and outdoor remain unchanged. Air flow rate within enthalpy exchanger embodies air velocity. The temperature exchange effectiveness, ranges from $90.95 \%$ at air flow rate of $226 \mathrm{~m}^{3} / \mathrm{h}$ to $86.36 \%$ at air flow rate of $260 \mathrm{~m}^{3} / \mathrm{h}$. All three efficiencies decreases as the air flow rate increases. When the air flow rate is reduced, the air flow velocity on both sides of the membrane decreases, and the fresh air and exhaust air stay in the core for a relatively long time, so 
that the heat transfer and humidity transfer through the membrane can be strengthened. But the absolute humidity ratio exchange effectiveness reduction is greater than the other two, this shows that it is affected by air velocity most greatly.

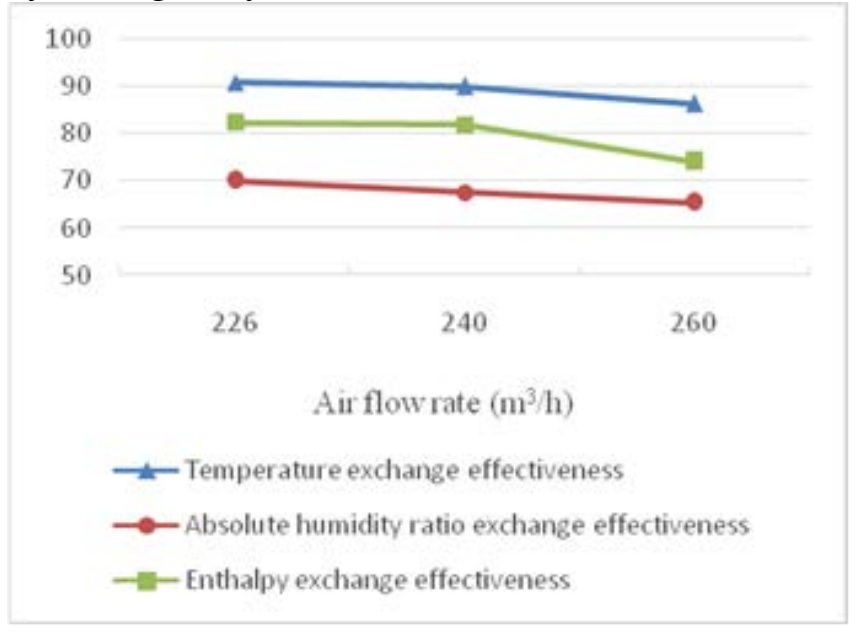

Fig. 4 Variation of the effectiveness with air velocity

Fig.5 and Fig.6 shows variation of the effectiveness of enthalpy exchanger with the difference of temperature and humidity ratio. The temperature exchange effectiveness and absolute humidity ratio exchange effectiveness change inversely proportional to the difference of temperature and humidity. With the change of temperature and humidity enthalpy exchange effectiveness remains basically unchanged. However, the enthalpy of air is related to temperature and humidity. Enthalpy exchange effectiveness should decrease with the other two.

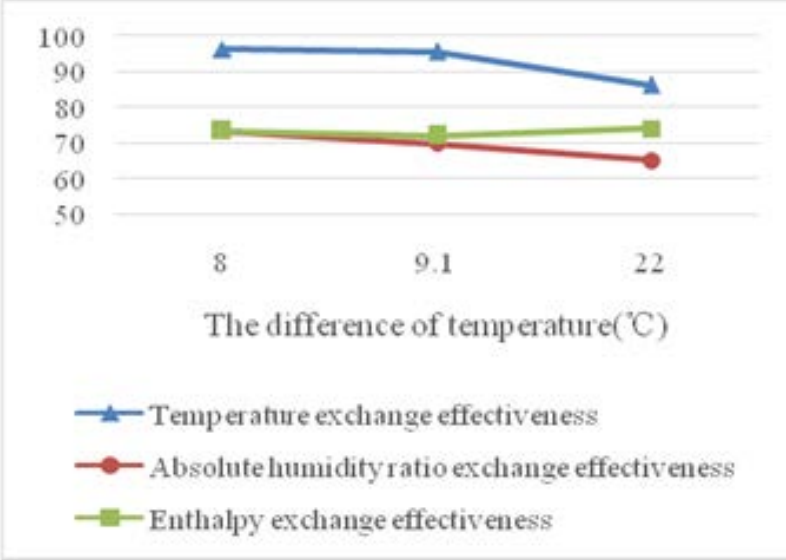

Fig. 5 Variation of the effectiveness with the difference of temperature

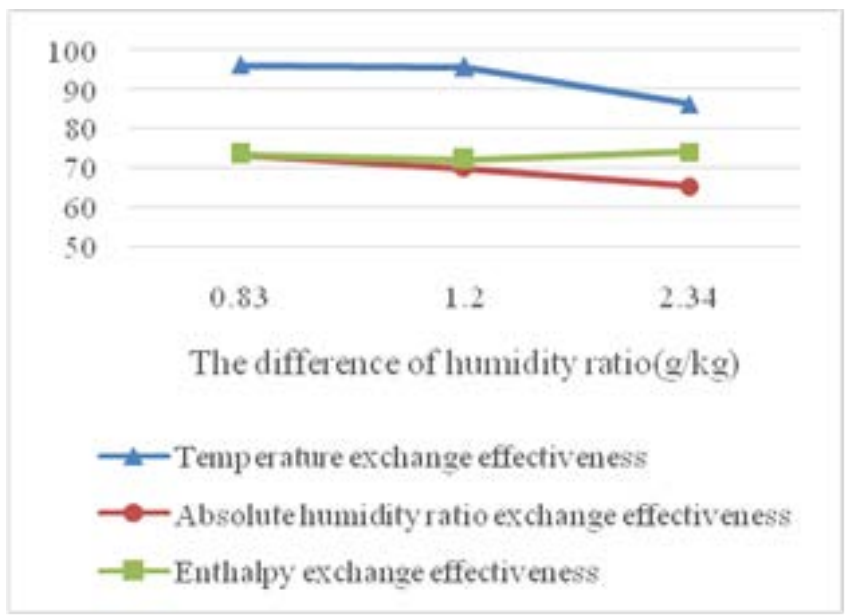

Fig. 6 Variation of the effectiveness with the difference of humidity ratio 
The enthalpy exchanger with natural ventilation has an overall dimension of $0.4 \mathrm{~m} \times 0.4 \mathrm{~m} \times 1.2 \mathrm{~m}$. The temperature transfer effectiveness of enthalpy exchanger is $80 \%$. Fig.7 shows variation of air flow rate with channel height and temperature difference. With the increase of channel height, the air flow rate increases obviously. The residence is too large to move for the air. In the same channel height, air flow rate increases with the increment of the temperature difference. When channel height is $8 \mathrm{~mm}$, air flow rate is from $53 \mathrm{~m}^{3} / \mathrm{h}$ to $133 \mathrm{~m}^{3} / \mathrm{h}$.

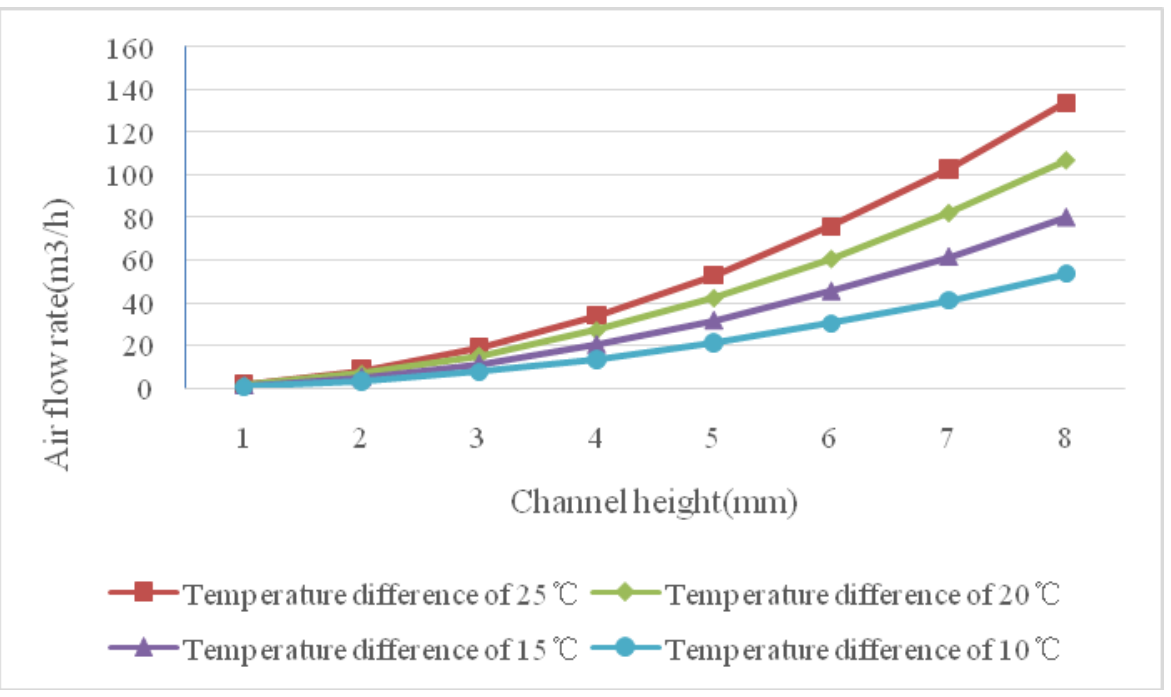

Fig. 7 Air flow rate of natural ventilation

Fig.8 shows variation of energy efficiency with temperature difference, when channel height is $8 \mathrm{~mm}$. Suppose the temperature transfer effectiveness of enthalpy exchanger with mechanical ventilation is $90 \%$ and enthalpy exchanger with natural ventilation is $80 \%$. Energy efficiency decreases with the increment of the temperature difference. Enthalpy exchanger with natural ventilation is more energy saving than mechanical ventilation.

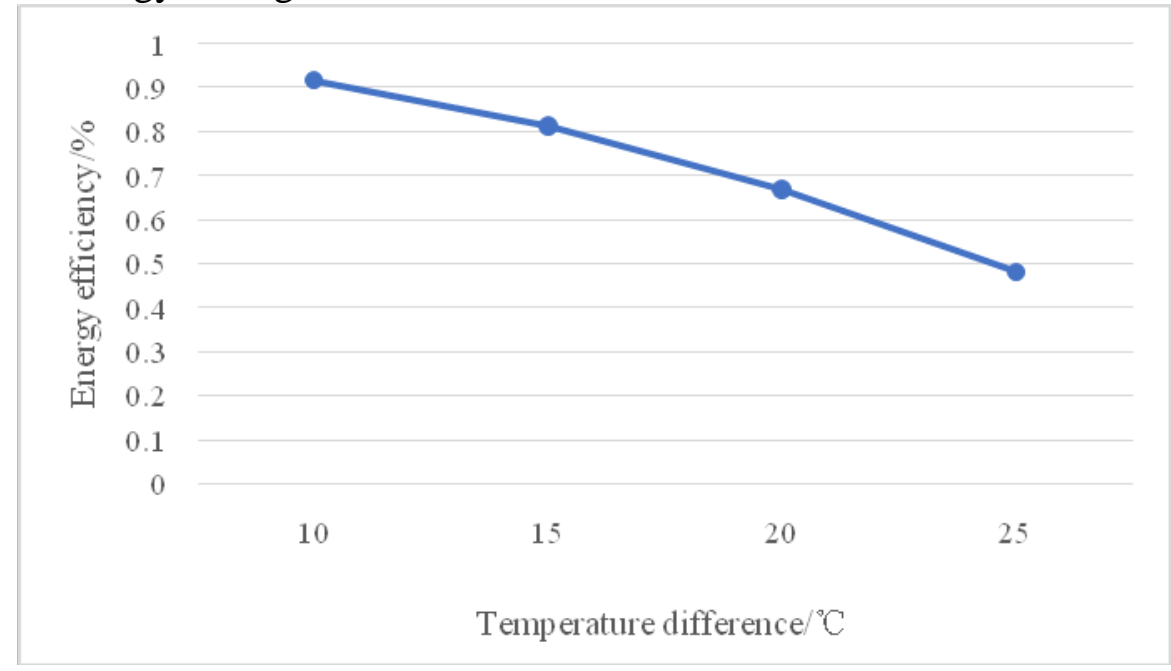

Fig. 8 Variation of energy efficiency with temperature difference

\section{Conclusions}

For the same enthalpy exchanger, with the increase of outdoor air flow rate and exhaust air flow rate, the temperature exchange effectiveness, the moisture exchange efficiency and the enthalpy exchange efficiency gradually decrease, absolute humidity ratio exchange effectiveness and enthalpy exchange effectiveness gradually decrease. The temperature exchange effectiveness and absolute humidity ratio exchange effectiveness change inversely proportional to the difference of temperature and humidity. 
When the channel height of enthalpy exchanger with natural ventilation is $8 \mathrm{~mm}$, air rate flow increase more greatly. Air rate flow is higher than $53 \mathrm{~m} 3 / \mathrm{h}$, when temperature difference is greater than $10^{\circ} \mathrm{C}$. Natural ventilation can meet the ventilation requirements in bedroom. Enthalpy exchanger with natural ventilation is more energy saving than mechanical ventilation.

\section{Acknowledgement}

This research is supported by Special Funds for Forest Scientific Research in the Public Welfare (No.201504610).

\section{Nomenclature}

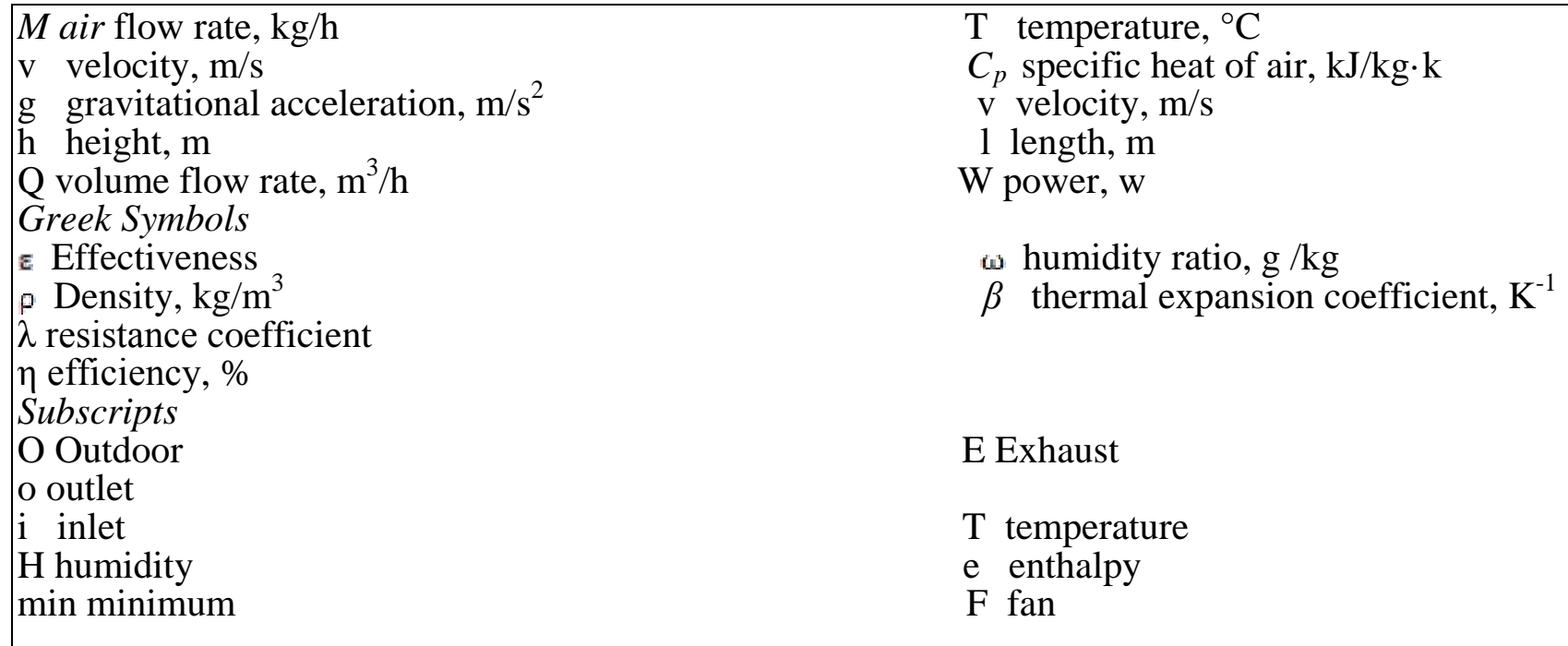

\section{References}

[1] Xinru Zhang, Lizhi Zhang, Hongmei Liu, et al. One-step fabrication and analysis of an asymmetric cellulose acetate membrane for heat and moisture recovery. Journal of Membrane Science.2011, 366(1-2):158-165.

[2] M. S. Kim, K. S. Lee, and S. Song, Int. J. Heat Fluid Flow, 29, 352 (2008).

[3] L. Z. Zhang, J. Memb. Sci., 360, 217 (2010).

[4] M. M. F. Hasan, G. Jayaraman, I. A. Karimi, and H. E. Alfadala, AIChE J., 56, 930 (2010).

[5] A. Sharma, S. D. Sharma, D. Buddhi, and D. W. Lee, Int. J. Energy Res., 30, 191 (2006). 